\title{
Pengaruh Saat Pemberian Pupuk Kandang dan Pupuk Anorganik Terhadap Pertumbuhan Wijen di Lahan Pasir Pantai
}

\author{
Dewi Ratna Nurhayati ${ }^{1)}$, Prapto, Y. ${ }^{2}$, Taryono $^{2}$, Hanudin, Eko ${ }^{2}$ \\ ${ }^{1}$ Pertanian, Universitas Slamet Riyadi, Surakarta \\ ${ }^{2}$ Pertanian UGM \\ Email: dewiratna2001@yahoo.com
}

\begin{abstract}
ABSTRAK
Tanah berpasir pesisir sebagai salah satu lahan marginal yang potensial menjadi menjadi lahan produktif berkelanjutan. Tanaman tahunan seperti budidaya wijen tepat untuk dikembangkan sebagai tanaman agribisnis di tanah berpasir pesisir dengan pupuk kotoran ayam atau pupuk organik dan pupuk anorganik melalui kombinasi pupuk kandang dan anorganik secara proporsional. Penelitian ini bertujuan untuk menentukan waktu terbaik pemberian pupuk terhadap pertumbuhan dan hasil dari wijen (Sesamum indicum L.). Penelitian ini dilakukan di Keburuhan, Purworejo, Pantai berpasir tanah, Laboratorium Pertanian Universitas Gadjah Mada, dari Mei hingga November 2014. Penelitian ini menggunakan percobaan faktorial Rancangan Acak Kelompok (RAK) dengan empat ulangan. Percobaan diatur dengan dua faktor. Faktor pertama adalah jenis varietas: Sumberrejo-1, Sumberrejo-2. Faktor kedua adalah, waktu pemberian pupuk kotoran ayam 11,25 ton/ha (75\% dari rekomendasi petani)+pupuk anorganik (N, P, K dosis pengganti kekurangan setara dengan 18,75 ton/ha pupuk kandang ayam. Variabel yang diamati adalah: tinggi tanaman, umur berbunga, jumlah cabang, volume akar. Data dianalisis dengan menggunakan analisis ragam pada 5\% tingkat signifikansi hasil penelitian menunjukkan bahwa berbunga tercepat (45 hari) adalah pada perlakuan kontrol Sumberrejo-1.
\end{abstract}

Kata kunci: lahan pantai berpasir, pupuk organik, di organik, Sumberrejo-1, Sumberrejo-2, Sesame (Sesamum indicum L.)

\section{Effect of Giving Manure and Inorganic Fertilizers on Growth Sesame in Land Sand Beach}

\begin{abstract}
Coastal sandy land as one of marginal land which potential become to be a sustainable productive land. Annual crops such as Sesame cultivation proper to developed as an agribusiness crops in coastal sandy land by chicken manure, or organic fertilizer and in organic fertilizer through the combination treatment of manure and inorganic proportionately. This study aimed to determine the best of time for fertilize on growth and yield of Sesame (Sesamum indicum L). This study conducted in Keburuhan, Purworejo, Coastal sandy land, Gadjah Mada's Agricultural station laboratory, from May until November 2014. This study used a factorial experiment Randomized Block Design (RBD) with four replications. Experiment arranged in with two-factor. First factor is the kind of variety: Sumberrejo-1, Sumberrejo-2. The second factor is, time of fertilize by chicken manure 11,25 tonnes/ha (75\% of farmers recommendation)+inorganic fertilizers $(N, P, K$ deficiency replacement dose equivalent to 18,75 tonnes/ha of chicken manure. Variable observed were: plant height, days to flowering, number of branch, root volume. The data analyzed by using analysis of variance at $5 \%$ level significance. The results showed that fastest flowering (45 days) was on the control treatmentin Sumberrejo-1.
\end{abstract}

Keywords: coastal sandy land, organic fertilizer, in organic, Sumberrejo-1, Sumberrejo-2 Sesame (Sesamum indicum L.) 


\section{PENDAHULUAN}

Wijen (Sesamum indicum L.) merupakan komoditas perkebunan rakyat yang potensial sebagai sumber minyak pangan yang banyak dibutuhkan. Tanaman ini mempunyai potensi agroindustri cerah diantaranya untuk keperluan bahan pangan, kue, penerangan, industri margarine, sabun, cat, produk parfum, bahan dasar produk farmasi, bahan ramuan obat, sebagai bahan/agen dispersi untuk membedakan macam insektisida. Wijen ditinjau dari nutrisinya mengandung 571,17 kalori; 4,10 mg copper; 2,44 mg Mn; 0,33 g tryptophan; 972,27 mg Ca; 350,02 mg Mg; 14,52 mg Fe; 627,24 mg P; 7,76 mg Zn; 0,77 mg; Vit B1 dan $11,74 \mathrm{~g}$ serat dalam $100 \mathrm{~g}$ biji (Hansen, 2009). Minyak wijen mengandung 50\% minyak nabati berkualitas tinggi yang dapat dimakan (edible oil) dan memiliki daya simpan lebih dari satu tahun tanpa mengalami kerusakan (tengik), karena mengandung antioksidan sesamol. Selain itu wijen kaya akan asam lemak tak jenuh, khususnya asam oleat dan asam linoleat yang bermanfaat menurunkan kolesterol dan mencegah atherosclerosis (Sharar dkk., 2000).

Meningkatnya kualitas hidup masyarakat yang diikuti dengan meningkatnya pola dan kesadaran hidup sehat memberikan dampak terhadap kebutuhan bahan pangan dan industri yang salah satunya berbahan dasar wijen, sehingga wijen masih layak dikembangkan (Rachman, 2005). Pengembangan wijen di lahan pasir pantai (LPP) dihadapkan pada tanah pasiran pantai yang memiliki kandungan unsur hara dan bahan organik rendah, kemampuan menyimpan air dan hara yang rendah, serta curah cahaya matahari yang terik sehingga suhu permukaan tanah tinggi dan angin cukup kencang (Masyudi, 2007). Untuk itu upaya meningkatkan produktivitas tanaman di lahan pasir pantai dapat dicapai melalui usaha perbaikan lahan dengan memberikan pupuk kandang sebagai sumber bahan organik yang berperan dalam proses perbaikan sifat kimia, fisika dan biologi tanah (Swift \& Sanchez, 1984), serta memperbaiki kesehatan tanah (Logan, 1990). Melalui peran kimianya, dari unsur esensial yang dihasilkannya, pupuk kandang mempunyai beberapa manfaat diantaranya dapat mendorong dan meningkatkan pembentukan klorofil daun sehingga meningkatkan kemampuan fotosintesis tanaman, meningkatkan vigor tanaman sehingga tanaman menjadi kokoh dan kuat, merangsang pertumbuhan cabang produksi dan meningkatkan pembentukan bunga maupun bakal buah, serta mengurangi gugurnya daun, bunga maupun bakal buah (Pal, 2004). Pemberian pupuk kandang dalam budidaya wijen di lahan pasir pantai perlu memperhatikan ketersediaan dan takaran yang diberikan. Kombinasi antara takaran yang diberikan dan macam pupuk kandang merupakan salah satu faktor yang dapat meningkatkan pertumbuhan, hasil tanaman dan kualitas minyak wijen. Tujuan penelitian ini untuk mengetahui saat pemberian pupuk terbaik terhadap pertumbuhan wijen di lahan pasir pantai.

\section{METODE PENELITIAN}

Penelitian ini dilakukan di lahan pasir pantai Keburuhan bulan September 2013. Penelitian diawali dengan membuat petak percobaan. Rancangan yang digunakan adalah Rancangan Acak Kelompok (RAK). Rancangan percobaan yang digunakan adalah Rancangan dasar RAK dengan 4 ulangan dengan 2 faktor, sebagai berikut:

Faktor 1: Jenis wijen (V)

$\mathrm{V} 1=$ wijen putih

$\mathrm{V} 2=$ wijen hitam

Faktor 2: Waktu aplikasi pemupukan (W)

$\mathrm{W} 1=$ diberikan 5 hari sebelum tanam

$\mathrm{W} 2=$ diberikan 0 hari/saat tanam

$\mathrm{W} 3$ = diberikan 5 hari setelah tanam. 
Dari kedua faktor tersebut, maka terdapat 6 variasi perlakuan, dengan 4 kali ulangan. Adapun variasi perlakuan:

$\begin{array}{lll}\text { V1W1 } & \text { V1W2 } & \text { V1 W3 } \\ \text { V2W1 } & \text { V2W2 } & \text { V2 W3 }\end{array}$

\section{Pelaksanaan Percobaan}

Membuat petak-petak percobaan di lahan pasir pantai $2,5 \times 3 \mathrm{~m}$, persiapan benih, penanaman dan pemupukan serta penjarangan maupun pemeliharaan tanaman. Kondisi lahan percobaan di awal penanaman dilakukan analisis tanah meliputi kondisi fisik, kimia dan biologi.

\section{Pengamatan}

Peubah yang diamati dalam penelitian ini adalah tinggi tanaman, jumlah cabang, volume akar dan saat berbunga.

\section{Analisis Data}

Data yang diperoleh akan dianalisis menggunakan uji statistik analisis varians (ANOVA). Apabila ada pengaruh perlakuan yang signifikan, maka analisis dilanjutkan dengan Uji Duncan untuk melihat perlakuan yang berbeda.

\section{HASIL DAN PEMBAHASAN}

Tabel 1. Pengaruh Saat Pemberian Pupuk Kandang Ayam dan Pupuk Anorganik (NPK) Terhadap RataRata Pertumbuhan dan Hasil Wijen di Lahan Pasir Pantai

\begin{tabular}{lllll}
\hline Perlakuan & \multicolumn{2}{c}{ Saat berbunga } & \multicolumn{2}{c}{ Jumlah cabang } \\
\cline { 2 - 5 } & V1 & V2 & V1 & V2 \\
\hline W0 & 42,5 & 40,25 & 3 & 2,75 \\
W 1 & 38,75 & 39,5 & 5 & 2,75 \\
W2 & 38,5 & 39,5 & 4 & 4,0 \\
W3 & 39,75 & 39,5 & 4,75 & 3,5 \\
Rerata V & 39,87 & 39,68 & 4,2 & 3,27 \\
LSD 5\% & 0,96 & 0,96 & 0,82 & 0,82 \\
KK \% & 9 & 9 & 20,7 & 20,7 \\
\hline
\end{tabular}

\begin{tabular}{|c|c|c|}
\hline \multirow[t]{2}{*}{ Perlakuan } & \multicolumn{2}{|c|}{$\begin{array}{c}\text { Tinggi tanaman } 8 \\
\text { minggu }\end{array}$} \\
\hline & V1 & $\mathrm{V} 2$ \\
\hline W0 & 113,2 & 127,2 \\
\hline W1 & 138 & 128,6 \\
\hline W2 & 139,1 & 140,1 \\
\hline W3 & 133,7 & 132,0 \\
\hline RerataV & 131 & 132,02 \\
\hline LSD $5 \%$ & 2,03 & 2,03 \\
\hline KK \% & 1,5 & 1,5 \\
\hline
\end{tabular}

Dari tabel tersebut diatas dapat disampaikan bahwa saat pemberian kombinasi pupuk memberikan kontribusi dalam meningkatkan tinggi tanaman pada mingggu ke 8 dibanding perlakuan tanpa pemupukan. Hal tersebut dikarenakan pupuk kandang ayam memiliki kandungan unsur hara NPK, maupun unsur mikro dan bersifat memperbaiki kondisi tanah. Dan pemberian pupuk anorganik (NPK), terdapat peningkatan tinggi tanaman, seperti pada perlakuan kecuali kontrol. Hal tersebut membuktikan bahwa kedua sifat pupuk tersebut saling berintegrasi menyediakan unsur hara untuk pertumbuhan tanaman. Pada perlakuan W2V1 dan W2V2 memiliki ketinggian yang tertinggi yaitu 139,1 dan 140,3 cm, hal tersebut dikarenakan unsur hara NPK yang terkandung dalam pupuk an-organik sangat besar dan cepat pengaruhnya bagi tanaman untuk mempercepat pertumbuhan vegetatif tanaman/tinggi tanaman (Dewanto, F., 2003) pengamatan hijau daun yang tertinggi pada perlakuan kombinasi (W2V1). Meningkatnya ketersediaan hara dalam tanah akan menyebabkan jumlah hara yang diserap oleh tanaman akan semakin besar. Dengan demikian pertumbuhan tanaman menjadi lebih baik. Jika unsur hara diserap tanaman maka semakin lama akan semakin berkurang yang kebutuhan hara $\mathrm{N}$ nya terpenuhi pada umur 6 minggu maka akan memiliki warna yang lebih hijau, seperti pada perlakuan K1 (menggunakan pupuk kandang ayam) hal 
tersebut disebabkan karena ketersediaan unsur hara pada pupuk kandang ayam bersifat slow release/tidak cepat tersedia bagi perakaran (Aribawa, I.B, dkk., 2004). Peranan unsur N salah satunya mensintesis klorofil yang dapat diamati kehijauan daun dari tabel diatas dapat disampaikan bahwa perlakuan saat pemupukan memberikan hasil yang nyata dari pada perlakuan tanpa pemupukan. Demikian halnya faktor macam varietas dan saat pemberian pupuk memberikan beda nyata terhadap pengamatan volume akar. Hal tersebut dapat dikatakan bahwa volume akar tergolong indikator pertumbuhan akar yang baik (Ibrahim et al., 2010). Selaras dengan hasil penelitian diatas, volume akar Varietas Sbr 2, memberikan hasil volume akar yang tertinggi. Hal tersebut selaras dengan pendapat Boparai et al. (1992) dan Yang (2004), yang menyampaikan bahwa peningkatan panjang akar dan volume akar dipengaruhi oleh pemberian pupuk kandang dan anorganik secara proporsional. Semakin besarnya volume akar yang dimiliki tanaman maka jangkauan akar juga semakin luas, sehingga mengakibatkan pengambilan unsur hara dan air oleh tanaman dapat lebih banyak. Unsur hara dan air dimanfaatkan tanaman sebagai substrat fotosintesis tanaman dan fotosintat akan digunakan untuk pertumbuhan tanaman sampai tanaman menghasilkan polong wijen. Dari tabel diatas dapat diperhatikan bahwa nilai laju asimilasi bersih dipengaruhi oleh saat pemberian pupuk dan macam varietas. Demikian halnya dengan kandungan minyak total wijen yang dipengaruhi oleh saat pemberian pupuk dan macam varietas. Jumlah cabang yang terbentuk untuk mendukung pertumbuhan polong wijen, juga dipengaruhi oleh macam varietas dan saat pemupukan karena dari cabang-cabang tersebut akan menghasilkan polong wijen yang tumbuh akibat dari munculnya bunga yang berkembang menjadi polong. Pengamatan kadar minyak tertinggi dicapai pada faktor perlakuan W2V1 dan W1V2. Hal ini menunjukkan terdapat perbedaan trend antar varietas akibat perlakuan saat pemupukan. Kejadian tersebut menunjukkan bahwa tanggapan varietas 1 cenderung lebih tinggi dibanding dengan tanggapan varietas 2 akibat perlakuan kombinasi pupuk pada pengamatan kadar minyak. Peran unsur hara yang diberikan melalui media tanam berupa pupuk kandang dan pupuk anorganik secara berimbang memberikan kelancaran dalam proses metabolisme tanaman pembentukan minyak wijen, hal tersebut tidak lepas dari kondisi lingkungan yang mempengaruhi seperti suhu lingkungan dan varietas tanaman.

\section{KESIMPULAN}

Berdasarkan hasil analisis dan pembahasan maka dapat disimpulkan bahwa saat pemberian pupuk kandang ayam dan pupuk anorganik memberikan pengaruh nyata terhadap tinggi tanaman, kandungan klorofil, kehijauan daun, saat berbunga, jumlah cabang, volume akar. Pupuk kandang dan pupuk anorganik diberikan pada saat tanam.

\section{DAFTAR PUSTAKA}

Aribawa, Ni Luh Kartini dan I.K. Kariada. 2004. Pengaruh beberapa jenis pupuk organik dan pupuk urea terhadap sifat tanah dan hasil kacang panjang di lahan kering pinggiran perkotaan Denpasar, Bali. Balai Pengkajian Teknologi Pertanian Bali.

Duhoon, A.J. Yotishi, M.R. Deshmukh and N.B. Singh. 2007. Optimization of sesame (Sesamum indicum L.) production through bio/natural inputs. All India Coordinated Research Project on Sesame and Niger (ICAR) J.N. Agriculture University, Jabalpur (M.P.) India-48200.

El-Habbasha, S.F., Abd El Salam, M.S. and Kabesh, M.O. 2007. Response of two sesame varieties (Sesamum indicum L.) to partial replacement of chemical 
fertilizers by bio-organic fertilizers. Research Journal of Agriculture and Biological Sciences 3(6), 563-571.

El-Nakhlawy and M.A. Shaheen. 2009. Response of seed yield, yield components and oil content to the sesame cultivar and nitrogen fertilizer rate diversity. JKAU: Met., Env. \& Arid Land Agric. Sci., Vol. 20, No. 2, pp: 21-31 (2009 A.D./1430 A.H.) Department of Arid Land Agriculture,Faculty of Meteorology, Environment and Arid Land Agriculture King Abdulaziz University, Jeddah, Saudi Arabia.

Harma. 2011. Growth and Yield of Sesame (Sesamum indicum L.) as Affected by Poultry Manure, Nitrogen and Phosphorus at Samaru, Nigeria. The Journal of Animal and Plant Sciences21(4), 2011, page 653-659.

Haruna and Abimiku. 2012. Yield of sesame (Sesamum indicum, L.) as influenced by organic fertilizer in the Southern Guinea Savana of Nigeria. Sustainable Agriculture Research 1(1), 66-69.

Hasan, B., I. Turgut and K. Turgut. 1999. Variation of certain characters and line selection for yield, oil, oleic and linoleic acids in the Turkish sesame populations. Journal of Agriculture and Forestry (23), 431-441.

Hwang, L.S. 2005. Sesame oil. Baileys Industrial Oil and Fat Product. TaipehNational Taiwan University.

Kastono, D. 2007. Aplikasi model rekayasa lahan terpadu guna meningkatkan peningkatan produksi hortikultura secara berkelanjutan di lahan pasir pantai. Jurnal Ilmu Pertanian vol: 3, Desember 2007. hal 112-116.

Kuzayli, M.V., J.W. Cowan and Z.I. Sabry. 1966. Nutritive value of middle eastern foodstuffs. II. Composition of pulses, seeds, nuts and cereal products of Lebanon. Journal of the Science of Food and Agriculture17, 82-84.
Mardjono, R., Supriyono dan H. Sudarmo. 2006. Galur-galur baru untuk pengembangan wijen di Indonesia. Makalah disampaikan pada sidang Komisi Pelepasan Varietas di Direktorat Jenderal Perkebunan Jakarta.

Musofie, A. 2008. Upaya pengembangan usaha tani di lahan pasir pantai melalui pemanfaatan limbah usaha peternakan. Makalah Seminar Nasional FTPUGM.

Nath, R., P. Chakraborty, P. Bandopadhyay, C. Kundu and A. Chakraborty. 2003. Analysis of relationship between crop growth parameters, yield and physical environment within the crop canopy of sesame (Sesamum indicum) at different sowing dates. Archives of Agron. And Soil Science49, 677-682.

Novania. 2001. Ekonomi teknik. Pusat Pengembangan Bahan Ajar UMB. hal 2-11.

Nzikou. 2009. Chemical composition on the seed and oil of sesame (Sesamum Indicum L.) grown in CongoBrazzaville. Advance Journal of Food Science and Technologi 1(1), 6-11.

Okpara. 2007. Effects of N, P Fertilizer Rate on The Growth and Yield of Sesame in The South astern Rain Forest Belt in Nigeria. Nigeria Agri.Journal(38),111.

Palaniappan, S.P., A. Jeyabal and S. Chelliah. 2003. Evaluation of integrated nutrient management in summer sesame (Sesamum indicum L.). Nagarjuna Agricultural Research and Development Institute C 15, Vikrampuri, Secunderabad-500 009, India.

Parwata, Arya, IGM. 2010. Kajian fisiologis ketahanan kekeringan tanaman jarak pagar (Jatropha curcas L.) di lahan pasir pantai. Disertasi. Sekolah Pascasarjana. Universitas Gajah Mada.Yogyakarta. 
Rajiman. 2010. Pemanfaatan bahan pembenah tanah lokal dalam upaya peningkatan produksi benih bawang merah di lahan pasir pantai Kulon Progo. Disertasi FP-UGM Yogyakarta.

Rifin, A. 1990. Pertumbuhan, hasil dan serapan hara $\mathrm{N}, \mathrm{P}$ dan $\mathrm{K}$ tanaman jagung pada berbagai fase cekaman air. Penelitian Pertanian 10(1), 19-21.

Roesmarkam, A dan N.W. Yuwono. 2002. Ilmu kesuburan tanah. Kanisius. Yogyakarta.

Rukmana. 1998. Budidaya Wijen. Kanisius. Yogyakarta.

Sanchez, P.A. 1992. Sifat dan pengelolaan tanah tropika. Alih bahasa: Amir Hamzah. Institut Teknologi Bandung. Bandung. 397 hal.

Sarjiyah. 1997. Budidaya tiga varietas kacang tanah di lahan pasir pantai, Dusun Gisik, Bugel, Kulon Progo, Yogyakarta. Agr. UMY 6(2), hal. 1-6.

Setyono, B. dan Suradal. 2005. Kelayakan usaha tani bawang merah di lahan pasir pantai dengan teknologi ameliorasi di Kab. Bantul Prov. DIY.

Balai Pengkajian Teknologi Pertanian Yogyakarta.
Sharar M.S., Ayub M, Choudhry M.A., Asif M. 2000. Growth and yield of sesame genotypes as influenced by NP application. Int J Agri Biol 1 (2), 8688.

Soenardi dan M. Romli. 1994. Pengaruh waktu tanam terhadap pertumbuhan dan produksi pada empat galur wijen. Prosiding Seminar Sehari Pengembangan Pertanian Berwawasan Lingkungan Dalam Era Globalisasi. Fakultas Pertanian, Universitas Pembangunan Nasional Veteran Jawa Timur, Surabaya. 10 September 1994.

Suddiyam, P., S. Maneekhao. 1997. Sesame (Sesamum indicum L.). A guide book for field crops production in Thailand. Field Crops Research Institute. Departmen Agriculture. 166 pp.

Syukur, A. 2005. Pengaruh pemberian bahan organik terhadap sifat-sifat nanah dan pertumbuhan caisim di tanah pasir pantai. Jurnal Ilmu Tanah dan Lingkungan 5(1), 30-38.

Widiana, G.N. 1994. Peranan EM-4 dalam meningkatkan kesuburan dan produktivitas tanah. Buletin Kyusei Nature Farming, 5, 28-43. 